\title{
Flap Viability after Direct Immediate Application of Negative Pressure Wound Therapy on Free Flaps: A Systematic Review and Pooled Analysis of Reported Outcomes
}

\author{
Jude L. Opoku-Agyeman, DO ${ }^{1}$ David V. Matera, BA ${ }^{2} \quad$ Jamee E. Simone, BS ${ }^{2}$ Amir B. Behnam, MD $^{3}$
}

${ }^{1}$ Department of Plastic and Reconstructive Surgery, Philadelphia
College of Osteopathic Medicine, Philadelphia, Pennsylvania
2 School of Osteopathic Medicine, Philadelphia College of
Osteopathic Medicine, Philadelphia, Pennsylvania
${ }^{3}$ Division of Plastic and Reconstructive Surgery, Department of
Surgery, The Reading Hospital, Tower Health System, West Reading,
Pennsylvania

J Reconstr Microsurg Open 2019;4:e77-e82.

\begin{abstract}
Address for correspondence Jude Opoku-Agyeman, DO, GME Office, Philadelphia College of Osteopathic Medicine, 4190 City avenue, Philadelphia, PA 19131 (e-mail: drjudeleo@gmail.com).
\end{abstract}

\begin{abstract}
Keywords

- NPWT

- free flap

- microvascular free flap

Background The use of negative pressure wound therapy (NPWT) devices has gained wide acceptance in the management of wounds. There have been a few reported cases of its use immediately after free tissue transfer. This is the first systematic review and pooled analysis on the immediate use of NPWT for free flaps with emphasis on the rate of free flap loss.

Methods The authors performed a systematic review that focused on the rate of total free flap loss after immediate application of NPWT. EMBASE, Cochrane Library, Ovid Medicine, MEDLINE, Google Scholar, and PubMed databases were searched from 1997 to April of 2019. Peer-reviewed articles published in the English language were included.

Results Ten articles were included in the review, yielding 211 free flap procedures. All studies were retrospective cohort studies except for two that were prospective studies and one that was a case series. The overall complete flap failure rate was $n=7$ (3.3\%). The most commonly reconstructed area was the lower extremity $(n=158$ [74.9\%]) followed by head and neck $(n=42$ [19.9\%]) and upper extremity $(n=11$ [5.2\%]). The vacuum pressure ranged from 75 to $125 \mathrm{~mm} / \mathrm{Hg}$. The time of application of the NPWT ranged from 5 to 7 days. The etiologies of wound defects were from trauma $(n=82$ [63.6\%]), tumor extirpation ( $n=43[33.3 \%])$, and infection and burn $(n=4[3.1 \%])$. Conclusion The immediate application of NPWT on free flaps does not seem to be associated with an increased risk of flap failure.
\end{abstract}

The use of negative pressure wound therapy (NPWT) devices have gained widespread acceptance since its introduction in 1997. It is currently used in the management of both acute and chronic wounds of different etiologies. The positive effect of NPWT on wound healing has been well documented. NPWT facilitates wound healing through multiple mecha- nisms of action both at the microscopic and macroscopic level. ${ }^{1,2}$ The mechanism of NPWT involves angiogenesis, wound contracture, and granulation formation. ${ }^{3,4}$ NPWT has been associated with significantly reduced rate of wound dehiscence, seroma, and skin necrosis compared with traditional dressings. ${ }^{5}$ The use of NPWT has extended to free flap received

June 10, 2019

accepted after revision

September 29, 2019
DOI https://doi.org/

10.1055/s-0039-3400450. ISSN 2377-0813.
Copyright $\odot 2019$ by Thieme Medical Publishers, Inc., 333 Seventh Avenue, New York, NY 10001, USA. Tel: +1(212) 584-4662.
License terms

(c) (1) $\ominus$ (\$) 
surgery. NPWT has been used to help heal donor sites. It is also applied directly on the free flap to secure split-thickness skin grafts (STSGs), help with wound healing, and help manage complications of flap surgery such as venous congestion. ${ }^{6}$ Evaluation of skin-grafted pedicled muscle flaps has also demonstrated a reduction of edema formation subsequent to NPWT use. ${ }^{7}$ Over the years, multiple concerns have been raised about the immediate application of NPWT device to free flaps. Some of the concerns include difficulty in monitoring flap viability and the potential for the NPWT to compress the newly anastomosed vessels, leading to flap vascular compromise or flap loss.

This systematic review aims to examine the immediate application of NPWT to free flaps and analyze the rate of flap failure.

\section{Methods}

\section{Research Design}

Our review followed guidelines published by the Centre for Reviews and Dissemination, the Cochrane Collaboration, and the Preferred Reporting Items for Systematic Reviews and Meta-Analyses criteria. ${ }^{8-10}$ This study complies with the principles of the Declaration of Helsinki. The protocol for this study has been registered with PROSPERO (CRD42019130464).

\section{Search Methodology and Strategy}

A comprehensive literature strategy was used to search the following databases: EMBASE, Cochrane Library, Ovid Medicine, MEDLINE, Google Scholar, and PubMed. The databases were searched from 1997 to April of 2019 on the immediate use of wound vacuum-assisted closure (VAC) on free flaps.
Bibliographies of all relevant primary articles and reviews were hand searched to identify articles missed by the electronic searches. We also attempted to identify gray literature on the topic by doing searches on European Union Clinical Trials Register, Open trials, PROSPERO, ISRCTN, Clinical Trial. gov, ProQuest, OpenThesis, and CINAHL.

The search strategy was developed to locate articles related specifically to the immediate use of NPWT of free flaps. The search used the English language keywords combined with Boolean logical operators. The following terms were used without any limits: "Negative pressure wound therapy" or "Negative pressure therapy" or "Negative pressure" or "NPWT" or "Vacuum-assisted closure" or "Vacuum assisted closure therapy" or "VAC" or "Vacuum-assisted dressing" and "free flap" or "microsurgical free flap" or "flaps" or "microvascular free flap" or " free tissue transfer."

\section{Selection Criteria}

The inclusion and exclusion criteria were defined before data collection was performed. Studies that evaluated the immediate use of NPWT after free flap reconstruction were included. All studies must have clearly stated whether patients underwent immediate application of NPWT after free flap reconstruction; if this was unclear, the article was excluded. Case series with more than five cases, retrospective, and prospective studies were included. - Fig. 1 outlines the selection process. Studies were excluded if they were not published in the English language, did not clearly state the number of patients, did not report the appropriate outcomes as stated, or were reviews or commentaries. Studies were limited to peer-reviewed studies published after 1997, when use of NPWT was first reported.

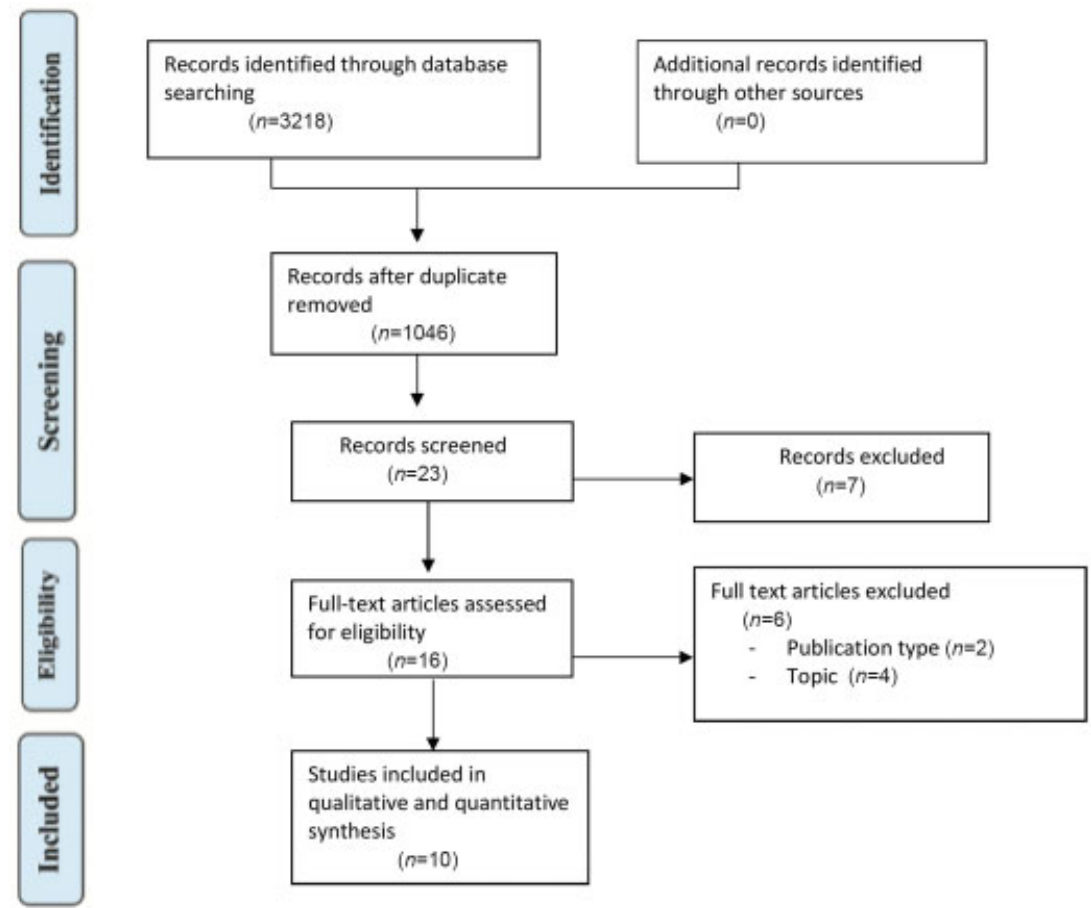

Fig. 1 Flow diagram of included studies. 
Table 1 Summary of characteristics of current literature evaluating immediate use of NPWT after free flap reconstruction

\begin{tabular}{|c|c|c|c|c|c|}
\hline References & $\begin{array}{l}\text { Year of } \\
\text { publication }\end{array}$ & Country & $\begin{array}{l}\text { Number of free flaps } \\
\text { with immediate } \\
\text { VAC application }\end{array}$ & Study type & $\begin{array}{l}\text { Level of } \\
\text { evidence }\end{array}$ \\
\hline $\begin{array}{l}\text { Hanasono and } \\
\text { Skoracki }^{11}\end{array}$ & 2007 & USA & 5 & Case series & IV \\
\hline Bannasch et $\mathrm{al}^{12}$ & 2008 & Germany & 5 & Retrospective review & IV \\
\hline Eisenhardt et al ${ }^{13}$ & 2010 & Germany & 26 & Retrospective review & IV \\
\hline Nelson et $\mathrm{al}^{14}$ & 2010 & USA & 14 & Retrospective review & IV \\
\hline Eisenhardt et al ${ }^{15}$ & 2012 & Germany & 15 & Randomized controlled study & II \\
\hline Henry et al ${ }^{16}$ & 2011 & USA & 13 & Retrospective review & IV \\
\hline Bi et al ${ }^{17}$ & 2018 & China & 24 & Retrospective review & IV \\
\hline Chim et al ${ }^{18}$ & 2018 & USA & 9 & Prospective controlled study & III \\
\hline Lin et $\mathrm{al}^{19}$ & 2018 & China & 31 & Retrospective review & IV \\
\hline Lenz et $a^{20}$ & 2018 & Germany & 69 & Retrospective review & IV \\
\hline
\end{tabular}

Abbreviations; NPWT, negative pressure wound therapy; VAC, vacuum-assisted closure.

\section{Data Extraction and Synthesis}

Key data extracted included authors of the publication, country, year of publication, study design, type of flap used in reconstruction, area of flap reconstruction, and etiology of reconstructed wounds. We also extracted additional data including rate of total free flap loss, age of patients, number of free flaps with immediate application of NPWT, pressure setting on NPWT, and days of NPWT application. Data extraction was performed independently by two reviewers. Disagreements were resolved through a third reviewer. A pooled data analysis was performed in Microsoft Excel. The rate of free flap failure was then calculated.

\section{Assessment of Study Quality and Bias in Included \\ Studies}

The methodological quality of studies was assessed using the Grading of Recommendation Assessment, Development and Evaluate system.

\section{Results}

Our search in the various databases yielded 3,218 publications. One thousand forty-six cases remained after removal of duplicates. The search finally yielded 10 publications. Characteristics of included studies are included in - Table $1 .{ }^{11-20}$ These studies fulfilled our inclusion and exclusion criteria after analysis of the full content of the articles. Results of quality analysis of each study are illustrated in -Table 2 .

Of the 10 articles included in the qualitative and pooled analysis, 4 of 10 were published in the United States, 4 of 10 were published in Germany, and 2 of 10 were published in China. All were published between 2007 and 2018. One of the 10 articles was a randomized controlled study, 1 of 10 was a prospective controlled study, 7 of 10 were retrospective reviews, and 1 of 10 was a case series. Five of 10 studies had a clearly stated follow-up period whereas 5 of 10 did not.

As shown in -Table 3, 211 total free flaps underwent immediate placement of NPWT. The average age of the

Table 2 Quality analysis of included studies using the GRADE system

\begin{tabular}{|l|l|l|l|}
\hline References & Study type & GRADE evaluation & Level of evidence \\
\hline Hanasono and Skoracki ${ }^{11}$ & Case series & Low quality & IV \\
\hline Bannasch et al ${ }^{12}$ & Retrospective review & Low quality & IV \\
\hline Eisenhardt et al ${ }^{13}$ & Retrospective review & Low quality & IV \\
\hline Nelson et al $^{14}$ & Retrospective review & Low quality & IV \\
\hline Eisenhardt et al $^{15}$ & Randomized controlled study & Moderate quality & II \\
\hline Henry et al $^{16}$ & Retrospective review & Low quality & IV \\
\hline${\text { Bi et al }{ }^{17}}^{\text {Chim et al }}{ }^{18}$ & Retrospective review & Low quality & IV \\
\hline Lin et al ${ }^{19}$ & Prospective controlled study & Moderate quality & III \\
\hline Lenz et al ${ }^{20}$ & Retrospective review & IV \\
\hline
\end{tabular}

Abbreviation: GRADE, Grading of Recommendation Assessment, Development and Evaluate. 


\begin{tabular}{|c|c|c|c|c|c|c|c|c|c|c|c|}
\hline 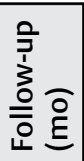 & $\stackrel{n}{m}$ & $\stackrel{\alpha}{z}$ & $\frac{o}{z}$ & $\mid \begin{array}{l}\sim \\
\emptyset\end{array}$ & $\frac{a}{z}$ & $\frac{o}{z}$ & $\bar{\infty}_{\infty}$ & $\sim$ & $m$ & $\frac{o}{z}$ & \\
\hline 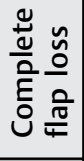 & 0 & 0 & $\sim$ & - & 0 & 0 & 0 & - & 0 & $m$ & $\begin{array}{l}\bar{\infty} \\
\stackrel{\infty}{m} \\
\stackrel{n}{r}\end{array}$ \\
\hline 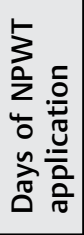 & in & in & in & in & in & in & $\wedge$ & Ln & in & $\mid \begin{array}{l}0 \\
1 \\
1 \\
\end{array}$ & 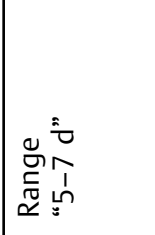 \\
\hline 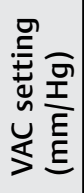 & $\begin{array}{l}8 \\
\frac{8}{1} \\
\frac{1}{n} \\
\end{array}$ & $\stackrel{\stackrel{n}{\rightleftharpoons}}{\sim}$ & $\stackrel{\stackrel{\Perp}{\simeq}}{\simeq}$ & $\stackrel{n}{\wedge}$ & $\stackrel{\stackrel{\sim}{\sim}}{\sim}$ & 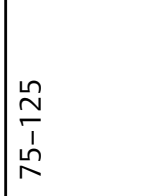 & $\stackrel{\stackrel{\Perp}{\cong}}{\cong}$ & $\stackrel{n}{\wedge}$ & $\stackrel{8}{\circ}$ & $\stackrel{\stackrel{n}{\sim}}{\simeq}$ & 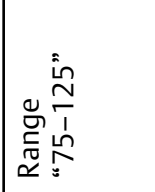 \\
\hline 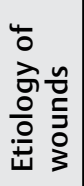 & 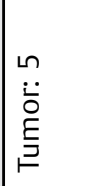 & 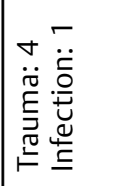 & 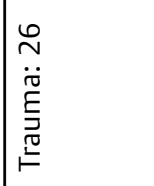 & 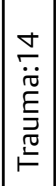 & 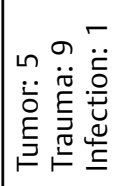 & $\frac{\alpha}{z}$ & 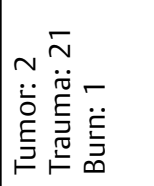 & 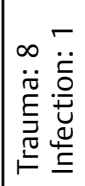 & 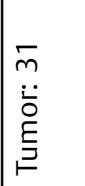 & $\frac{\alpha}{z}$ & 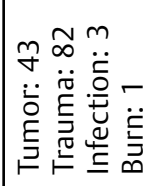 \\
\hline 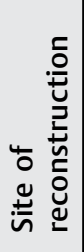 & \begin{tabular}{|l} 
\\
\\
$n$ \\
$\ddot{z}$ \\
$\not$ \\
$I$
\end{tabular} & نَّ & $\mid \begin{array}{l}\stackrel{0}{N} \\
\dot{u}\end{array}$ & \begin{tabular}{|l|} 
\pm \\
$\dot{u}$ \\
$ن$
\end{tabular} & نَّ & $\begin{array}{l}- \\
\ddot{z}\end{array}$ & 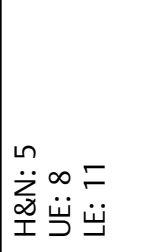 & 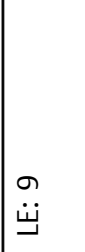 & $\begin{array}{l}\bar{m} \\
\ddot{z} \\
\not \\
\underline{I}\end{array}$ & \begin{tabular}{|l} 
\\
0 \\
0 \\
$\dot{ت}$
\end{tabular} & 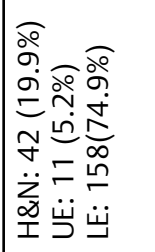 \\
\hline 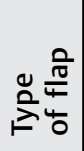 & $\begin{array}{l}m \sim \\
\ddot{\theta} \ddot{\varkappa}\end{array}$ & 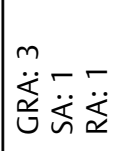 & 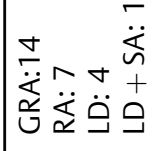 & 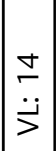 & 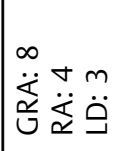 & 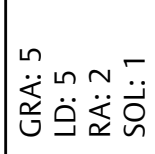 & 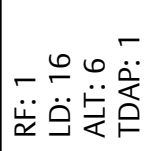 & 吕 & 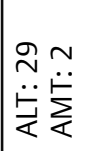 & $\frac{\alpha}{z}$ & 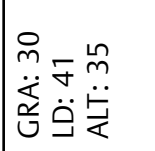 \\
\hline 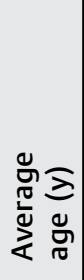 & $\begin{array}{l}0 \\
\text { فे } \\
\text { Lे }\end{array}$ & $\stackrel{\infty}{\stackrel{\infty}{m}}$ & $\begin{array}{l}\circ \\
\dot{\gamma}\end{array}$ & \begin{tabular}{|l}
$n$ \\
$\tilde{\gamma}$ \\
$\dot{\gamma}$
\end{tabular} & $\frac{0}{\operatorname{rn}}$ & $\stackrel{\circ}{\stackrel{\circ}{m}}$ & $\begin{array}{l}\infty \\
\text { g் }\end{array}$ & $\begin{array}{l}\varphi \\
\dot{q}\end{array}$ & $\begin{array}{l}0 \\
\dot{0}\end{array}$ & $\frac{\alpha}{2}$ & 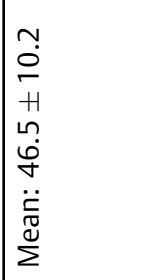 \\
\hline 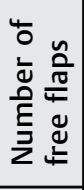 & in & in & $\stackrel{\wp}{\sim}$ & $\nexists$ & $\stackrel{\llcorner}{\sim}$ & $\stackrel{m}{r}$ & $\stackrel{\sim}{\sim}$ & $a$ & $\bar{m}$ & 8 & $\overline{\bar{N}}$ \\
\hline 忞 & 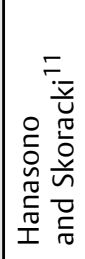 & 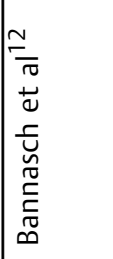 & 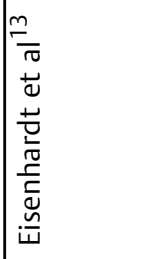 & 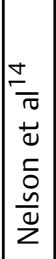 & 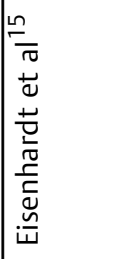 & 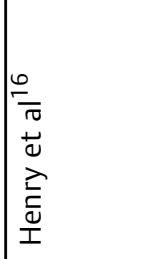 & $\begin{array}{l}=\frac{1}{\pi} \\
\bar{c} \\
\overline{0} \\
\bar{\infty}\end{array}$ & 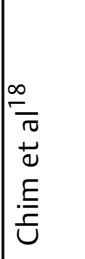 & 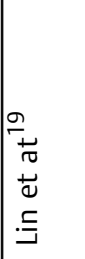 & 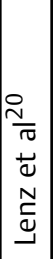 & $\frac{\pi}{\circ}$ \\
\hline
\end{tabular}


patients was $46.5 \pm 10.2$ years. The reconstructed areas included the head and neck region ( $n=42$ [19.9\%]), lower extremity ( $n=158$ [74.9\%]), and upper extremity $(n=11$ [5.2\%]). The etiology of the defects included traumatic wounds $(n=82 \quad[63.6 \%])$, tumor extirpation $(n=43$ [33.3\%]), and infections and burns $(n=4$ [3.1\%]). A variety of free flaps were used, the most common being a latissimus dorsi flap ( $n=41)$, anterolateral thigh (ALT) flap ( $n=35)$, and gracilis flap $(n=29)$. Less common flaps reported included vastus lateralis flap, radial forearm flap, soleus flap, serratus anterior flap, rectus abdominis flap, anteromedial thigh flap, and thoracodorsal artery perforator flap.

The pressure setting on the NPWT device ranged from 75 to $125 \mathrm{~mm} / \mathrm{Hg}$ and the time from placement of the VAC to initial flap evaluation ranged from 5 to 7 days. The total flap failure rate was $n=7$ (3.3\%).

Publication bias using a funnel plot could not be performed due to the small number of included studies (10 studies) and the fact that most of the studies were not controlled to allow generation of odds ratios or relative risks.

\section{Discussion}

Our systematic review and pooled analysis showed that the immediate application of NPWT to a newly constructed free flap does not increase the rate of flap failure. The use of NPWT for wound management has enjoyed a stable niche in wound care and reconstructive surgery. Its indications have expanded to include its application after pedicled flap surgery and free flap surgery. In free flap surgery, NPWT is used for many indications, including use on donor sites to facilitate healing. It is also used to manage wound complication at the free flap site. One of the main effects of the NPWT is the reduction in edema. ${ }^{21}$ Free flaps, especially muscle flaps, tend to have a bulky appearance and low overall aesthetic satisfaction among patients, which sometimes necessitates a revision or debulking procedures. The use of the NPWT to ameliorate this problem makes the prospects very palatable to plastic surgeons. By using NPWT, significant edema reduction has been observed, which in return allows for improved tissue perfusion. NPWT has been shown to decrease flap edema, flap thickness, and aesthetic outcomes compared with conventional dressing. ${ }^{18}$ The results demonstrated the use of NPWT on fasciocutaneous flaps. Thirty-five ALT free flaps underwent application of NPWT. The indication for use of NPWT on these flaps was to reduce flap edema, remove exudate and infectious material from the wound bed, promote granulation tissue formation, and draw wound edges together. ${ }^{17,18}$

NPWT has also been demonstrated to result in increased integration of STSG when used instead of traditional bolster dressings. ${ }^{11,22}$ The use of the NPWT also allows for patient comfort by avoiding daily dressing changes required of the traditional dressing. This is also important when securing a skin graft to areas where bolsters will be difficult to apply, especially in the head and neck region. Our review revealed that the NPWT dressing is being applied to all areas of the body, including the head and neck, lower extremities, and upper extremities with no increased risk of flap failure. Our study also demonstrates that NPWT was applied for 5 to 7 days before it was taken off the flap.

Despite these advantages, NPWT is only rarely used in the setting of microsurgical reconstruction. Many concerns have been raised about the use of NPWT on free flaps. The two most common concerns include the inability to clinically monitor the transferred tissue and the possibility of flap compression by the subatmospheric pressure exerted by the device, leading to free flap compromise and free flap loss. ${ }^{13}$

Traditionally, the flap failure rate has been estimated to be $<5 \%,{ }^{23}$ with most flap failures occurring in the lower extremity. Our review shows a pooled flap failure rate of 3.3\% after the application of wound VAC. This rate is well within the reported range for free flap failure rate. All reported flap loss in our review occurred in the lower extremity.

As mentioned above, one of the concerns of the application of NPWT to free flaps is the perceived lack of clinical monitoring of the free flap. Over the years, many strategies have been developed to overcome this shortcoming. One of the strategies involves creating a small window in the NPWT device dressing to allow direct visualization and examination of the flap. This also allows the use a handheld Doppler to check for arterial signals. The second strategy involves the use of implantable Doppler devices. The evolution of the implantable Doppler device has been found to be equal if not better than just clinical examination and use of a hand-held Doppler. The implantable Doppler probe has been proven to be applicable in large clinical series for monitoring of free flaps. ${ }^{24,25}$ Lenz et al found that the use of implantable devices allowed the flap to be monitored adequately with higher salvage rate compared with use of traditional dressings. ${ }^{20}$

Our study has several limitations. First, it was limited by the quality and quantity of the literature on the use of NPWT on free flaps. Only 10 studies met our inclusion criteria. Majority of the studies were retrospective in nature. There was only one randomized controlled study. Second, only studies published in the English language were reviewed. It is possible that there are some publications in the non-English language literature on this topic. Another major limitation is that 4 out of 10 articles included in this study were from the same institution presenting a potential for bias. ${ }^{12,13,15,20}$

\section{Conclusion}

This study is the first systematic review and pooled analysis examining the flap loss rate after the immediate application of NPWT on free tissue flaps. Our review demonstrates that the immediate use of NPWT on free flaps does not appear to increase the rate of flap failure.

Funding

None.

Conflict of Interest

None declared. 


\section{References}

1 Orgill DP, Bayer LR. Negative pressure wound therapy: past, present and future. Int Wound J 2013;10(Suppl 1):15-19

2 Webb LX, Pape HC. Current thought regarding the mechanism of action of negative pressure wound therapy with reticulated open cell foam. J Orthop Trauma 2008;22(10, Suppl): S135-S137

3 Malmsjö M, Ingemansson R, Martin R, Huddleston E. Wound edge microvascular blood flow: effects of negative pressure wound therapy using gauze or polyurethane foam. Ann Plast Surg 2009; 63(06):676-681

4 Malmsjö M, Ingemansson R, Martin R, Huddleston E. Negativepressure wound therapy using gauze or open-cell polyurethane foam: similar early effects on pressure transduction and tissue contraction in an experimental porcine wound model. Wound Repair Regen 2009;17(02):200-205

5 Ge D. The safety of negative-pressure wound therapy on surgical wounds: an updated meta-analysis of 17 randomized controlled trials. Adv Skin Wound Care 2018;31(09):421-428

6 Yu P, Yu N, Yang X, Jin X, Lu H, Qi Z. Clinical efficacy and safety of negative-pressure wound therapy on flaps: a systematic review. J Reconstr Microsurg 2017;33(05):358-366

7 Blackburn JH II, Boemi L, Hall WW, et al. Negative-pressure dressings as a bolster for skin grafts. Ann Plast Surg 1998;40 (05):453-457

8 Centre for Reviews and Dissemination. Systematic Reviews: CRD's Guidance for Undertaking Reviews in Health Care 2009. York, United KingdomCentre for Reviews and Dissemination, University of York; 2009. Available at: www.york.ac.uk/media/crd/ Systematic_Reviews.pdf. Accessed March 1, 2019

9 Higgins JPT, Green S, eds. Cochrane Handbook for Systematic Reviews of Interventions, Version 5.1.0 (updated March 2011). Available at: https://training.cochrane.org/handbook. Accessed March 1, 2016

10 Moher D, Liberati A, Tetzlaff J, Altman DG; PRISMA Group. Preferred reporting items for systematic reviews and meta-analyses: the PRISMA statement. PLoS Med 2009;6(07):e1000097

11 Hanasono MM, Skoracki RJ. Securing skin grafts to microvascular free flaps using the vacuum-assisted closure (VAC) device. Ann Plast Surg 2007;58(05):573-576

12 Bannasch $\mathrm{H}$, Iblher N, Penna V, et al. A critical evaluation of the concomitant use of the implantable Doppler probe and the vacuum assisted closure system in free tissue transfer. Microsurgery 2008;28(06):412-416

13 Eisenhardt SU, Momeni A, Iblher N, et al. The use of the vacuumassisted closure in microsurgical reconstruction revisited: applica- tion in the reconstruction of the posttraumatic lower extremity. J Reconstr Microsurg 2010;26(09):615-622

14 Nelson JA, Kim EM, Serletti JM, Wu LC. A novel technique for lower extremity limb salvage: the vastus lateralis muscle flap with concurrent use of the vacuum-assisted closure device. J Reconstr Microsurg 2010;26(07):427-431

15 Eisenhardt SU, Schmidt Y, Thiele JR, et al. Negative pressure wound therapy reduces the ischaemia/reperfusion-associated inflammatory response in free muscle flaps. J Plast Reconstr Aesthet Surg 2012;65(05):640-649

16 Henry SL, Weinfeld AB, Sharma SK, Kelley PK. External Doppler monitoring of free flaps through negative pressure dressings. J Reconstr Microsurg 2011;27(04):215-218

17 Bi H, Khan M, Li J, Pestana IA. Use of incisional negative pressure wound therapy in skin containing free tissue transfer. J Reconstr Microsurg 2018;34(03):200-205

18 Chim H, Zoghbi Y, Nugent AG, Kassira W, Askari M, Salgado CJ. Immediate application of vacuum assisted closure dressing over free muscle flaps in the lower extremity does not compromise flap survival and results in decreased flap thickness. Arch Plast Surg 2018; 45(01):45-50

19 Lin PY, Liou TL, Lin KC, Hsieh MH, Chien CY, Hsieh CH. Immediate negative pressure wound therapy after free flap transfer for head and neck cancer surgery. Laryngoscope 2018;128(11):2478-2482

20 Lenz Y, Gross R, Penna V, Bannasch H, Stark GB, Eisenhardt SU. Evaluation of the implantable Doppler probe for free flap monitoring in lower limb reconstruction. J Reconstr Microsurg 2018;34 (03):218-226

21 Morykwas MJ, Simpson J, Punger K, Argenta A, Kremers L, Argenta J. Vacuum-assisted closure: state of basic research and physiologic foundation. Plast Reconstr Surg 2006;117(7, Suppl):121S-126S

22 Llanos S, Danilla S, Barraza C, et al. Effectiveness of negative pressure closure in the integration of split thickness skin grafts: a randomized, double-masked, controlled trial. Ann Surg 2006;244 (05):700-705

23 Bui DT, Cordeiro PG, Hu QY, Disa JJ, Pusic A, Mehrara BJ. Free flap reexploration: indications, treatment, and outcomes in 1193 free flaps. Plast Reconstr Surg 2007;119(07):2092-2100

24 Kind GM, Buntic RF, Buncke GM, Cooper TM, Siko PP, Buncke HJ Jr. The effect of an implantable Doppler probe on the salvage of microvascular tissue transplants. Plast Reconstr Surg 1998;101 (05):1268-1273, discussion 1274-1275

25 Rosenberg JJ, Fornage BD, Chevray PM. Monitoring buried free flaps: limitations of the implantable Doppler and use of color duplex sonography as a confirmatory test. Plast Reconstr Surg 2006;118(01):109-113, discussion 114-115 